\title{
Effect of Pharmacological Blocking of TLR-4 on Osteoarthritis in Mice
}

\author{
Matthew Siebert, Spencer K. Wilhelm, Jeffrey Z Kartchner, David Mecham, Paul R. Reynolds and David L. Kooyman*
}

Brigham Young University, Department of Physiology and Developmental Biology, 4005 LSB, Provo, UT 84602, USA

\begin{abstract}
Receptors for Advanced Glycation End Products (RAGE) and Toll Like Receptor 4 (TLR-4) have been shown to play a role in the development of Osteoarthritis (OA). We have previously shown that knocking out RAGE in mice slows the disease progression in articular cartilage of the knee. The objective of this study was to determine if application of the compound TAK-242, a TLR-4 specific inhibitor, in conjunction with knocking out RAGE could further attenuate the disease. Destabilization of the medial meniscus of RAGE KO and Wild Type (WT mice) was performed, and severity of OA was qualitatively analyzed through two standardized scoring systems (Mankin and OARSI). We also performed immunohistochemistry to analyze levels of HtrA1, Mmp-13 and Tgf- $\beta 1$, known biomarkers for the disease. Surprisingly, addition of the TLR blocker did not offer additional protection against OA in mice when RAGE had been knocked out, and its application to WT mice exacerbated the severity of OA. We conclude that while blockage of the RAGE pathway alone is beneficial to the attenuation of OA, hampering the TLR-4 pathway offers no protective benefits.
\end{abstract}

Keywords: Osteoarthritis; Mice; TLR-4; TAK-242

\section{Introduction}

Osteoarthritis (OA) is a prevalent chronic disease with over 27 million people in the US presenting some symptoms [1]. OA is recognized to be a multifactorial disease with the majority of adults subject to risk factors such as obesity, joint-loading, acute injury, aging and joint-misalignment. As the US population advances particularly in age and obesity, the incidence of $\mathrm{OA}$ is also likely to increase significantly.

Once thought to be a result of abnormal or excessive mechanical stress that physically degraded joint articular surfaces, current research has increasingly shifted the understanding of OA from a disease of "wear and tear" to a metabolically active process with several inflammatory biomarkers driving OA progression, for review see [2]. We and others have previously demonstrated the importance of Tgf-B1, HtrAl and Mmp-13 in the progression of OA [3-6]. As part of the inflammatory pathway driving OA progression, matrix degrading proteases HtrA1 and Mmp-13 are secreted by chondrocytes into the pericellular and extracellular matrix, resulting in reduced matrix integrity and function.

TGF-B1 has been shown to participate in chondrocyte regulation with prolonged exposure leading to the early stages of cartilage pathologies $[7,8]$. Specifically, TGF-B1 has been shown to play both a chondroprotective role through ALK5 (Smad2/3 pathway) and a degenerative effect through activation of ALK1 (Smad1/5/8) [9]. Indeed, we have previously shown that early expression of Tgf-B1 in OA leads to an initial surge of chondrocyte proliferation. This response is, however, overwhelmed by expression of catabolic proteins such as $\mathrm{HtrA} 1$ which are induced by elevated levels of Tgf-B1 $[3,10]$. The Receptor for Advanced Glycation End-products (RAGE) is a cellsurface receptor expressed in a wide array of cell types. Research has shown RAGE to be a pattern recognition receptor that binds endogenous S100/calgranulins, amyloid- $\beta$-peptide, and HMGB-1 (or amphoterin) to initiate proinflammatory cascades such as those mediated by MAP kinases, NF-KB and pro-inflammatory cytokines IL-1, Tnf-alpha and Tgf-B [11].

Our previous studies have demonstrated that even when RAGE is knocked out, TGF-B levels are not significantly different from wild type (WT) mice [3]. This observation suggests an alternate transduction mechanism that results in production of Tgf-B. Toll-like receptor-4 (TLR-4) belongs to a family of pattern recognition receptors triggered by pathogen-associated molecular patterns (PAMPs) and alarmins may represent such an alternate pathway [12]. TLR-4 has been found to block anabolic response in articular cartilage and prevent repair of injured cartilage [13]. Not only does TLR-4 prevent cartilage repair, but activation of this receptor induces expression of proinflammatory cytokines, increasing inflammatory response that triggers destruction of cartilage $[14,15]$. When activated by the appropriate ligands, TLR4 has been shown to increase Tgf-B1 via increased NF-KB signaling. This increase in TGF-B1 has been shown to then upregulate Mmp-13 expression with the result of cartilage destruction [16].

The compound TAK-242 has been shown to act as a TLR- 4 specific inhibitor [17,18]. Because TLR-4 and RAGE lead to inflammatory responses, we expect simultaneous inhibition of both pathways to attenuate OA. We compared the effect of TAK-242 on the progression of OA in both wild type and RAGE knock-out (RAGE KO) mice which had undergone knee destabilization surgery according to established procedures [19]. We report that contrary to our hypothesis, TAK-242 increased the severity of $\mathrm{OA}$ in a dose-dependent manner in wild-type mice but had no significant effect on OA in RAGE KO mice.

\section{Materials and Methods}

\section{Mice and joint destabilization procedure}

RAGE KO mice that lack membrane and soluble RAGE were generated on a C57BL/6 background [20]. The RAGE KO have

*Corresponding author: David L. Kooyman, Brigham Young University, Department of Physiology and Developmental Biology, 4005 LSB, Provo, UT 84602, USA, Tel: $801-$ 422-6399; Fax: 801-422-0004; E-mail: david_kooyman@byu.edu

Received August 12, 2015; Accepted September 02, 2015; Published September 12, 2015

Citation: Siebert M, Wilhelm SK, Kartchner JZ, Mecham D, Reynolds PR, et al (2015) Effect of Pharmacological Blocking of TLR-4 on Osteoarthritis in Mice. J Arthritis 4: 164. doi:10.4172/2167-7921.1000164

Copyright: $\odot 2015$ Siebert M, et al. This is an open-access article distributed under the terms of the Creative Commons Attribution License, which permits unrestricted use, distribution, and reproduction in any medium, provided the original author and source are credited. 
previously been shown to lack any RAGE expression [20]. Wild type/control mice were the same C57BL/6 background (The Jackson Laboratory, Bar Harbor, ME, USA; Strain Name: C57BL/6; Stock number 000664). The mice were randomized for sex and a destabilization of the medial meniscus (DMM) procedure was performed on 28-day-old-RAGE KO $(n=18)$ and wild type $(n=$ 16) mice. Mice were anesthetized using an intraperitoneal injection of 0.5-0.7 cc Avertin IP [0.5 ml Avertin solution ( $15.5 \mathrm{ml}$ tert-amyl alcohol to $25 \mathrm{~g}$ Avertin) in $39.5 \mathrm{ml}$ normal saline solution] and the skin surrounding the right knee joint was prepped by clipping the fur and washing with an iodine surgical scrub followed by $70 \%$ alcohol. The remainder of the procedure was performed under a Wild Heerbrugg 355110 (Wild Heerbrugg AG, Switzerland) surgical microscope using sterile technique. The medial meniscotibial ligament was exposed by blunt dissection and the joint area was visualized. The meniscotibial ligament was subsequently transected using a number 11 scalpel to allow the displacement of the medial meniscus. Displacement of the meniscus was confirmed visually. The joint capsule and skin was both closed using 7-0 absorbable Vicryl suture (Ethicon, Inc., Somerville, NJ, USA). These procedures were conducted under a protocol 10-0901 approved by the Brigham Young University IACUC.

\section{Administration of TAK-242}

TAK-242 (CLI-095, InvivoGen, San Diego, CA, USA) was solubilized in DMSO (Sigma-Aldrich, St. Louis, MO, USA) at concentrations of $0.1 \mathrm{uM}$ and $1 \mathrm{uM}$ with the wild-type and RAGE KO control groups receiving vehicle without TAK-242. Wild type mice were divided into three treatment groups; vehicle without TAK-242 (control), $0.1 \mathrm{uM}$ TAK-242 and $1 \mathrm{uM}$ TAK-242 ( $\mathrm{n}=3,7,6$ respectively). RAGE KO mice were similarly divided ( $\mathrm{n}=6,6,6$ respectively). TAK242 or vehicle was administered on days $0,7,14$, and 21 post-surgery.

\section{Tissue processing}

Wild type mice and RAGE KO mice at 28 days post-surgery were euthanized by isoflurane USP (Abbott Laboratories, North Chicago, IL, USA), and right knee joints were excised and fixed in $4 \%$ paraformaldehyde overnight. Each sample was then washed with $\mathrm{H} 2 \mathrm{O}$ over a period of $6 \mathrm{~h}$ with the $\mathrm{H} 2 \mathrm{O}$ being exchanged every 30 min. The tissues were decalcified in a formic acid solution that was changed every 2-3 days for a period of 2-3 weeks. Decalcification of each sample was confirmed through an ammonium oxalate reaction, and tissues were embedded in paraffin wax using an automated tissue processor (ThermoFisher Scientific, MA, USA). Paraffin blocks were prepared with the knee joint bent at a $120^{\circ}$ angle, with the anterior tibial surface flush with the cutting surface [21].

Right knee and TM joint blocks were sectioned at $6 \mu \mathrm{m}$ through the entire joint from the anterior surface to the posterior using a Microm HM 325 microtome (Thermo Scientific, Kalamazoo, MI, USA). Four to five sections were placed per glass microscope slide, yielding $~ 35-50$ slides or $\sim 160-225$ sections per joint, depending on the animal.

\section{Histological analysis}

Histopathology was documented by Safranin O and Fast Green staining of knee sections from all wild type and RAGE KO treatment groups. Using a light microscope equipped with an Olympus digital camera (Olympus America Inc., Center Valley, PA, USA), photographs of each knee joint were taken at 200 and $400 \times$ magnifications.

The articular cartilage in a representative section from each stained slide was analyzed using a modified Mankin score to quantify the pathological state of each joint, with a score of 0 representing unaltered articular cartilage and 14 representing severe OA. Overall modified Mankin scoring was based on a subset of scores including cartilage erosion score (0-6), chondrocyte periphery staining (0-2), spatial arrangement of chondrocytes $(0-3)$, and background staining intensity (0-3) (Table 1) [21,22]. Modified Mankin scores were assigned by three independent investigators who were blinded both to the strain of mouse (wild type or RAGE KO) and treatment group. Statistical significance of the combined Mankin scores for all wild type and RAGE KO treatment groups was obtained via mixed model analysis of variance conducted by the Department of Statistics at Brigham Young University.

\section{Immunohistochemical analysis}

Immunohistochemistry was performed on sections of mouse knee joints from wild type $(0,0.1,1 \mathrm{uM}$ treatment groups) and RAGE KO mice $(0,0.1,1 \mathrm{uM}$ treatment groups). Separate slides were stained with antibodies against HtrA-1, Tgf- $\beta 1$, and Mmp-13. Each slide was deparaffinized and then blocked for $1 \mathrm{~h}$ in PBS supplemented with 5\% bovine serum albumin (Sigma-Aldrich, St Louis, MO, USA; B2518) and $0.05 \% \mathrm{Na}$ Azide (Sigma-Aldrich, St Louis, MO, USA; S2002). Primary antibodies against HtrA-1 (ab38611) were purchased from Abcam (Cambridge, MA, USA), against TGF- $\beta 1$ (ab92486) from Abcam (Cambridge, MA, USA), and against Mmp-13 (AB8120) from Chemicon (Temecula, CA, USA). All antibodies were diluted 1:200, applied to specimens, and incubated overnight at $4^{\circ} \mathrm{C}$. On the second day, samples were rinsed with PBS and then incubated with an avidin/ biotin $\mathrm{ABC}$ mix (Vectastain elite ABC Kit, Vector Laboratories, Inc., Burlingame, CA, USA). Slides were rinsed a second time with PBS and incubated with biotinylated secondary antibody. After a third PBS rinse, a color reaction was initiated to achieve a red/brown stain using a peroxidase substrate (VECTOR NovaRED substrate kit, Vector Laboratories, Burlingame, CA, USA). Slides were then dehydrated and

\begin{tabular}{|l|c|}
\hline Cartilage Erosion Scoring Criteria & Score \\
\hline Smooth non-eroded cartilage & 0 \\
\hline Rough non-eroded cartilage & 1 \\
\hline Superficial fibrillation & 2 \\
\hline Separation of uncalcified from calcified cartilage & 3 \\
\hline Erosion of uncalcified cartilage only & 4 \\
\hline Erosion extending into calcified cartilage & 5 \\
\hline Erosion down to subchondral bone & 6 \\
\hline Chondrocyte periphery staining & \\
\hline Normal & 0 \\
\hline Slightly enhanced & 1 \\
\hline Intensely enhanced & 2 \\
\hline Spatial arrangement of chondrocytes & 0 \\
\hline Normal & 1 \\
\hline Diffuse hypercellularity & 2 \\
\hline Clustering & 3 \\
\hline Hypocellularity & \\
\hline Background staining intensity & 0 \\
\hline Normal & 1 \\
\hline Slight reduction & 2 \\
\hline Moderate reduction & 3 \\
\hline Severe reduction & 4 \\
\hline No dye noted & \\
\hline
\end{tabular}

The Modified Mankin score is comprised of four categories: cartilage erosion score, chondrocyte periphery staining, spatial arrangement of chondrocytes, and background staining intensity.

Table 1: Modified Mankin score table. 
mounted. A cover slip was applied prior to photographing. Negative controls were prepared by staining without the addition of primary antibody. Staining was analyzed quantitatively by calculating the percentage of cells staining positive for the respective biomarkers and the total number of chondrocytes in a defined $211 \times 1358$ pixel area of articular cartilage immediately distal to the tibial plateau. All quantitative analysis was performed using ImageJ (National Institutes of Health, Bethesda, MD, USA). Cell counting was done by three independent investigators who were blinded both to the strain of mouse (RAGE KO vs. wild type) and experimental group (control, $0.1 \mathrm{uM}$, or $1 \mathrm{uM})$. The quantitative results were subsequently analyzed statistically by logical regression.

\section{Results}

\section{Rage KO protected against exacerbation of OA by TAK-242}

Both wild type and RAGE KO mice were visualized and analyzed histologically (Figure 1). Cartilage degradation was analyzed histologically by presence of superficial fibrillations, early increase in proteoglycan expression, chondrocyte hypercellularity and clustering. Mankin scores were compared within genotypes across treatment groups. There was no significant difference in the severity of OA observed in the RAGE KO mice, regardless the concentration of TAK-242 administered. In wild type mice, however, indications of osteoarthritis increased dose-dependently upon application of TAK$242(\mathrm{p}=0.0055)$. Mankin scores were also compared between genotypes at the defined treatment levels and RAGE KO mice had significantly lower Mankin scores than wild type at the $1 \mathrm{uM}$ concentration $(\mathrm{p}=0.0416)$ (Figure 2).

\section{Tgf-B1 levels staining patterns similar for both Rage $\mathrm{KO}$ and wild type mice}

Immunohistochemical analysis of both RAGE KO and wild type mice across all treatment concentrations revealed positive staining for Tgf-B1 (Figure 3). RAGE KO mice showed a dose-dependent increase in Tgf-B1 as the concentration of TAK- 242 was increased, although the increase observed between $0.1 \mathrm{uM}$ and $1 \mathrm{uM}$ treatments was not statistically significant (Figure 4). Wild type mice showed no significant change at any treatment level. Tgf-B1 expression in RAGE KO differed significantly from wild type at the vehicle $(\mathrm{p}<0.0001)$ and $0.1 \mathrm{uM}$ level $(\mathrm{p}=0.0012)$, but not at the $1 \mathrm{uM}$ level.

\section{HtrA1 increases with TAK-242 in Rage KO, but remains constant in wild type}

TAK-242 dose-dependently increased HtrA1 expression in RAGE KO mice but did not have any significant effect on WT (Figure 5). We found that HtrA1 levels were significantly lower in control RAGE KO than WT mice $(\mathrm{p}<0.0001)$ but increased significantly with concentration of TAK-242. HtrA1 expression was significantly higher in RAGE KO mice receiving $1 \mathrm{uM}$ TAK-242 than wild type mice receiving the same treatment $(\mathrm{p}<0.0001)$ (Figure 6).

\section{Mmp-13 increases dose-dependently in both Rage KO and wild type}

MmP-13 was observed in all tissues analyzed by immunohistochemistry (Figure 7). We observed that in both RAGE $\mathrm{KO}$ and wild type mice, the percentage of chondrocytes staining positive for Mmp-13 increased dose-dependently $(\mathrm{p}<0.0001$ and $\mathrm{p}<0.0001$, respectively) with application of TAK-242 (Figure 8 ). The difference between expression in RAGE $\mathrm{KO}$ and wild type mice was

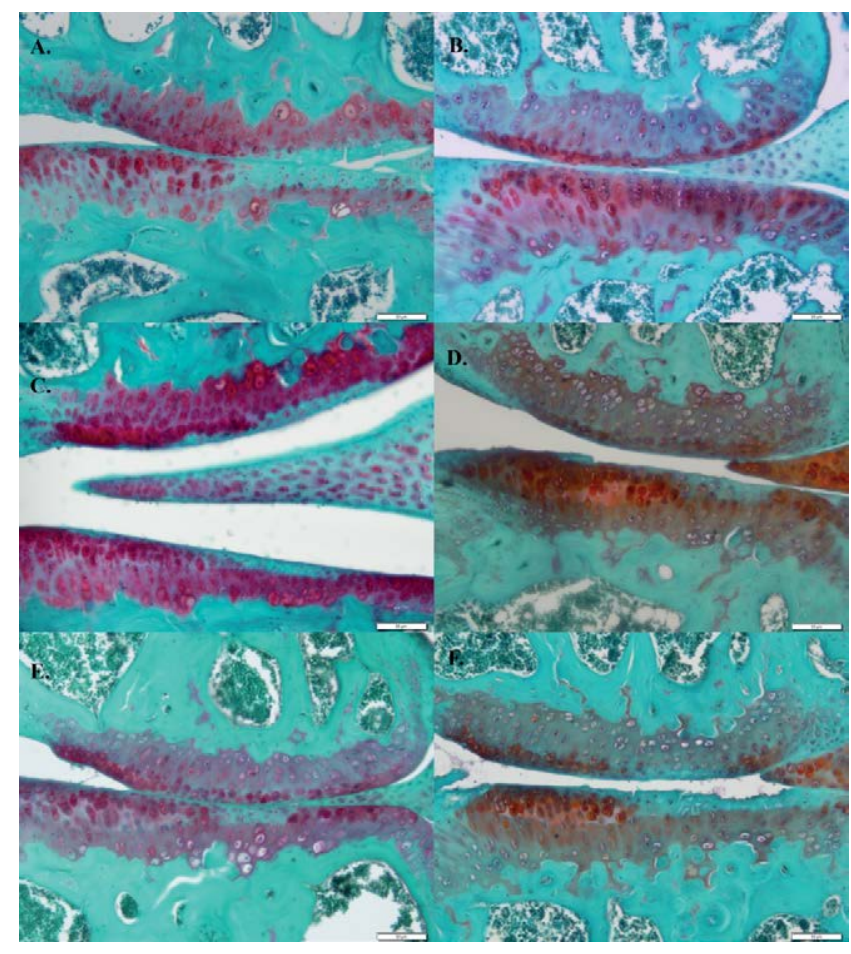

Figure 1: Saffarinin orange staining of knee sections. Knee sections from RAGE KO ( $A=0 ; C=0.1 \mathrm{uM} ; E=1 \mathrm{uM})$ and WT mice $(B=0 ; D=0.1 \mathrm{uM} ; F=1 \mathrm{uM})$. Space bar equals $50 \mu \mathrm{m}$.

\section{Modified Mankin Score}

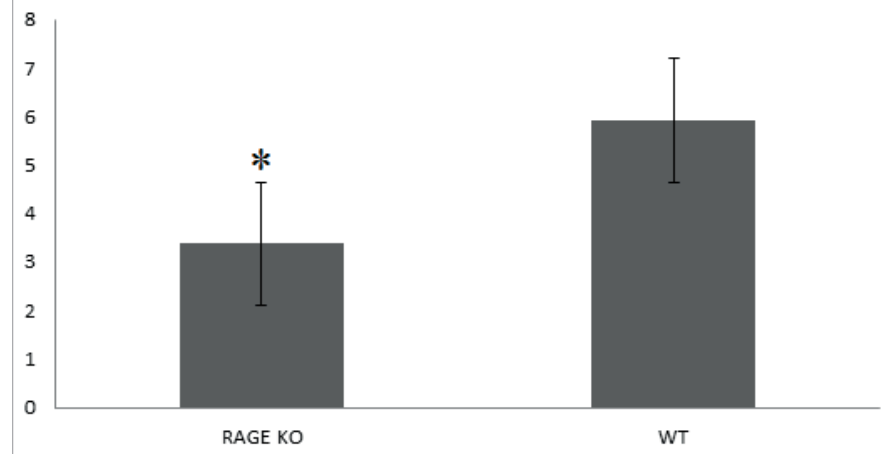

Figure 2: Modified Mankin score comparison between genotypes. Modified Mankin Scores showed an overall significantly $(p=0.0416)$ lower score in the RAGE KO group when compared to that of the WT group at all TAK-242 concentrations.

very significant at all concentrations of TAK-242. Wild type mice were much more likely to stain for Mmp-13 than their RAGE KO counterparts at the control, $0.1 \mathrm{uM}$ and $1 \mathrm{uM}$ treatment levels. This broad difference between RAGE KO and wild type expression of Mmp13 corresponds to the increase in cartilage degradation observed in wild type mice with administration of TAK-242.

\section{Immunohistochemical staining of Mmp-13 corresponds with severity of cartilage degradation}

Upon statistical analysis, a significant increase in severity of cartilage degradation was observed between the control and $1 \mathrm{uM}$ treatment groups in wild type mice. This corresponded directly to 
Citation: Siebert M, Wilhelm SK, Kartchner JZ, Mecham D, Reynolds PR, et al. (2015) Effect of Pharmacological Blocking of TLR-4 on Osteoarthritis in Mice. J Arthritis 4: 164. doi:10.4172/2167-7921.1000164

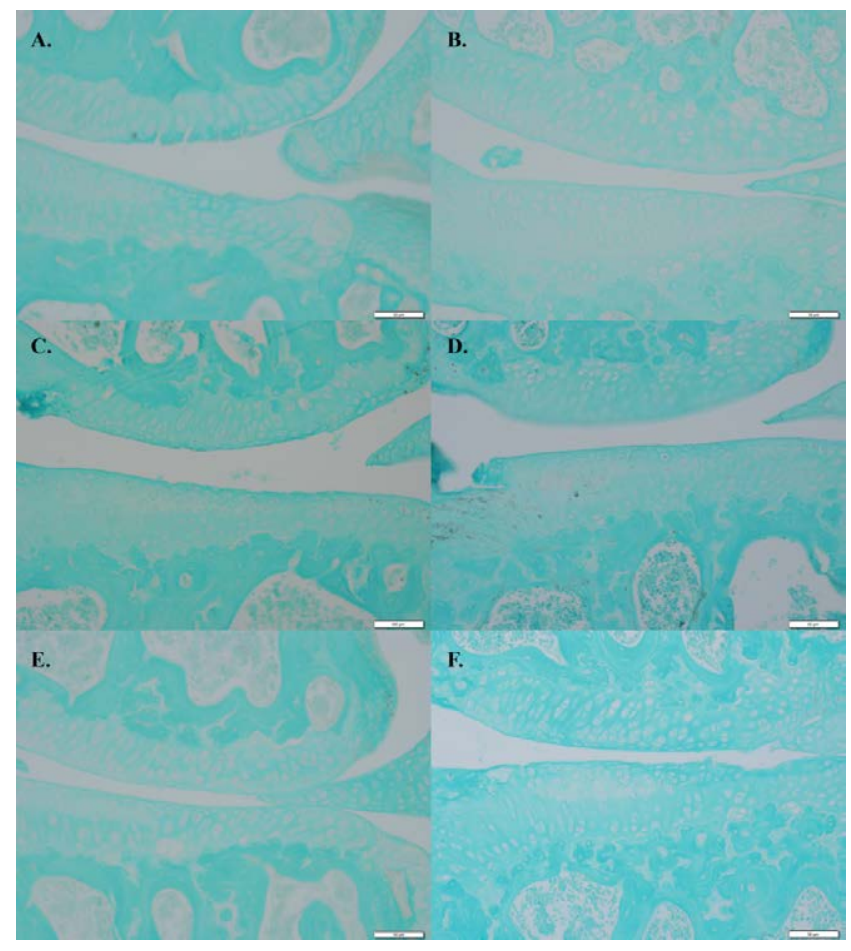

Figure 3: Immunohistochemical Staining of Knee Sections for Tgf-B1. Knee sections from RAGE KO ( $A=0 ; C=0.1 \mathrm{uM} ; E=1 \mathrm{uM})$ and WT mice $(B=0 ; D=0.1$ $\mathrm{uM} ; \mathrm{F}=1 \mathrm{uM})$. Space bar equals $50 \mu \mathrm{m}$.

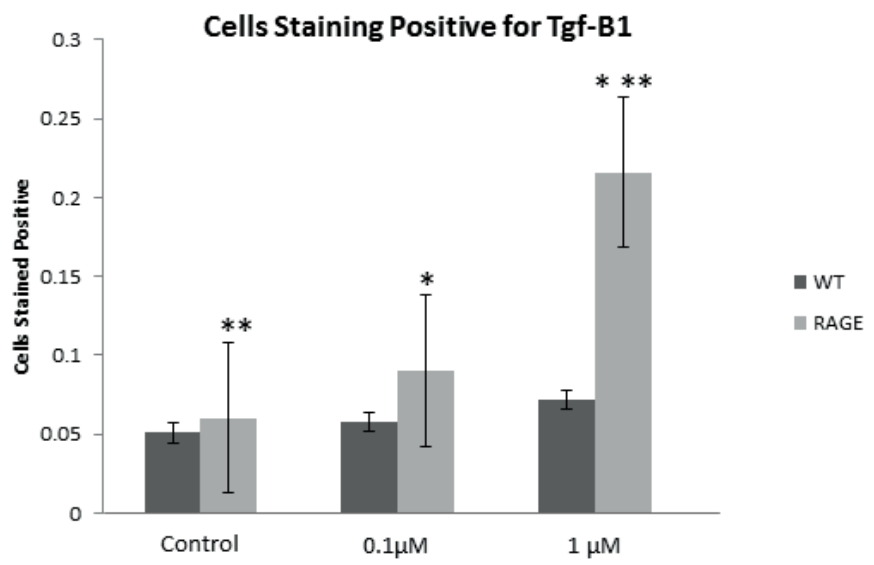

Figure 4: Percentage OF cells staining positive FOR tgf-b1. RAGE KO mice showed a dose-dependent increase in Tgf-B1 that was significantly higher between $1 \mu \mathrm{M}$, control $(\mathrm{p}<0.0001)$ and $0.1 \mu \mathrm{M}(\mathrm{p}=0.0012)$ but not between control and $0.1 \mu \mathrm{M}$. Wild type mice showed no significant change at any treatment level.

a significant increase in Mmp-13 in those same treatment groups $(\mathrm{p}<0.0001)$. Though a significant increase was observed between control, $0.1 \mathrm{uM}(\mathrm{p}<0.0001)$ and $1 \mathrm{uM}(\mathrm{p}=0.0078)$ treatment groups in RAGE KO mice, the overall expression of Mmp-13 was still significantly lower $(\mathrm{p}<0.0001)$ than wild type mice and no statistical difference was observed in severity of cartilage degradation.

\section{Discussion}

Currently, the standard treatment for OA is prescription of NSAIDs to reduce joint inflammation and pain followed by joint replacement surgery when cartilage is fully eroded. No satisfactory treatment has been found to halt the progression of OA. Given the metabolic nature of OA, a study of the biomarkers involved in OA progression as well as the associated signaling pathways is necessary to produce a treatment [2]. In our current study, we have demonstrated the involvement of TLR- 4 and TGF-B1 in the pathogenesis and progression of OA.

The Mmp-13 expression patterns in wild type mice correlate with the increased severity of OA. Conversely, the lack of significant change

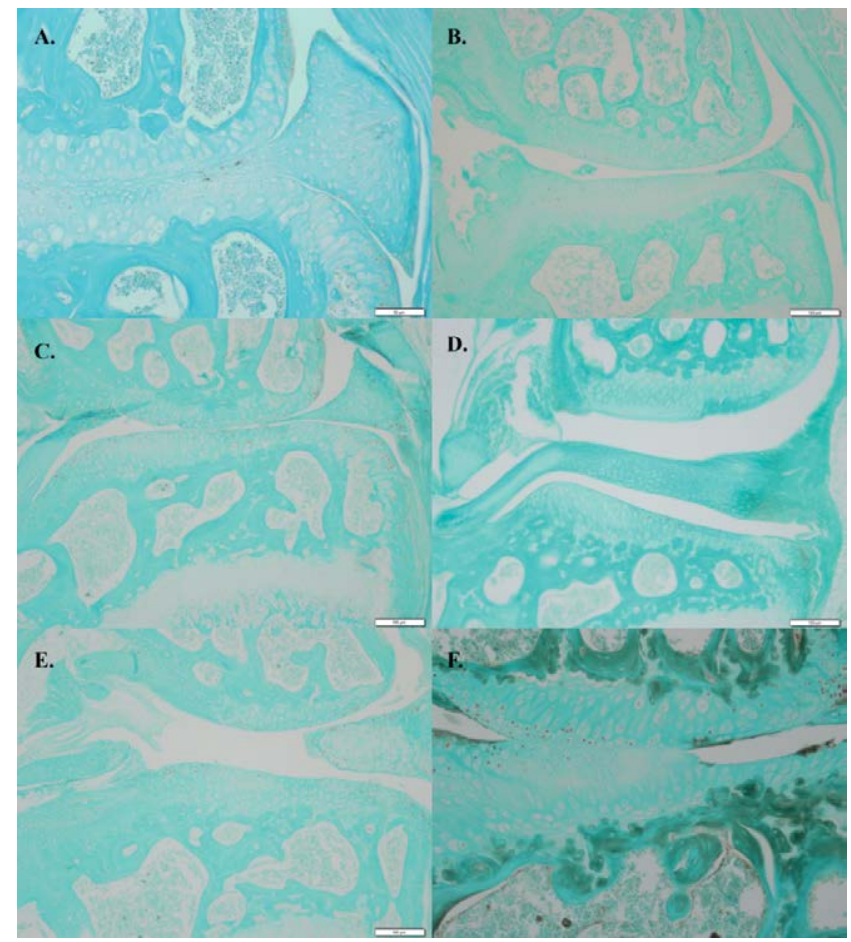

Figure 5: Immunohistochemical staining of knee sections for HtrA1. Knee sections from RAGE KO $(A=0 ; C=0.1 \mathrm{uM} ; E=1 \mathrm{uM})$ and WT mice $(B=0 ; D=0.1$ $\mathrm{uM} ; \mathrm{F}=1 \mathrm{uM})$. Space bar equals $50 \mu \mathrm{m}$.

\section{Cells Staining Positive For HtrA1}

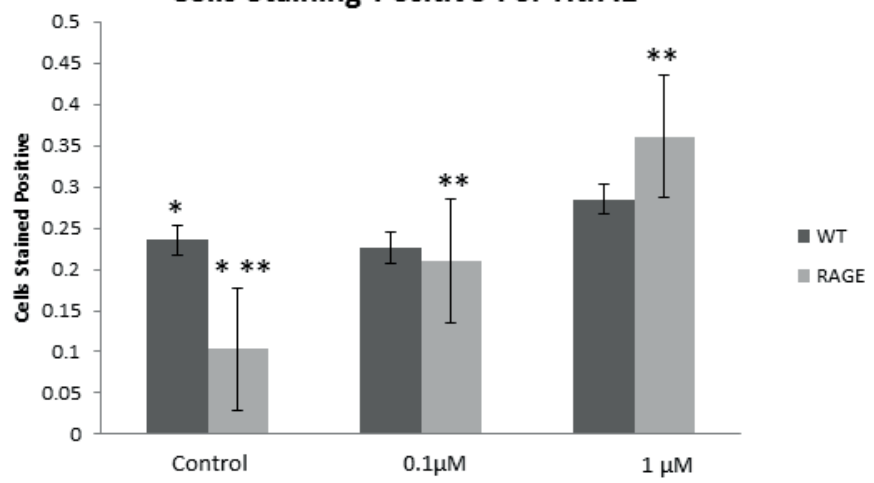

Figure 6: Percentage of cells staining positive for HtrA1. A dose-dependent increase in $\mathrm{HtrA} 1$ expression was observed in RAGE KO mice receiving TAK$242(p<0.0001))$. There was no significant dose effect on WT mice. HtrA1 levels were significantly lower $(p<0.0001)$ in control RAGE KO but increased significantly $(p<0.0001)$ with concentration of TAK-242 with HtrA1 expression being highest in RAGE KO mice receiving 1 uM TAK-242. 


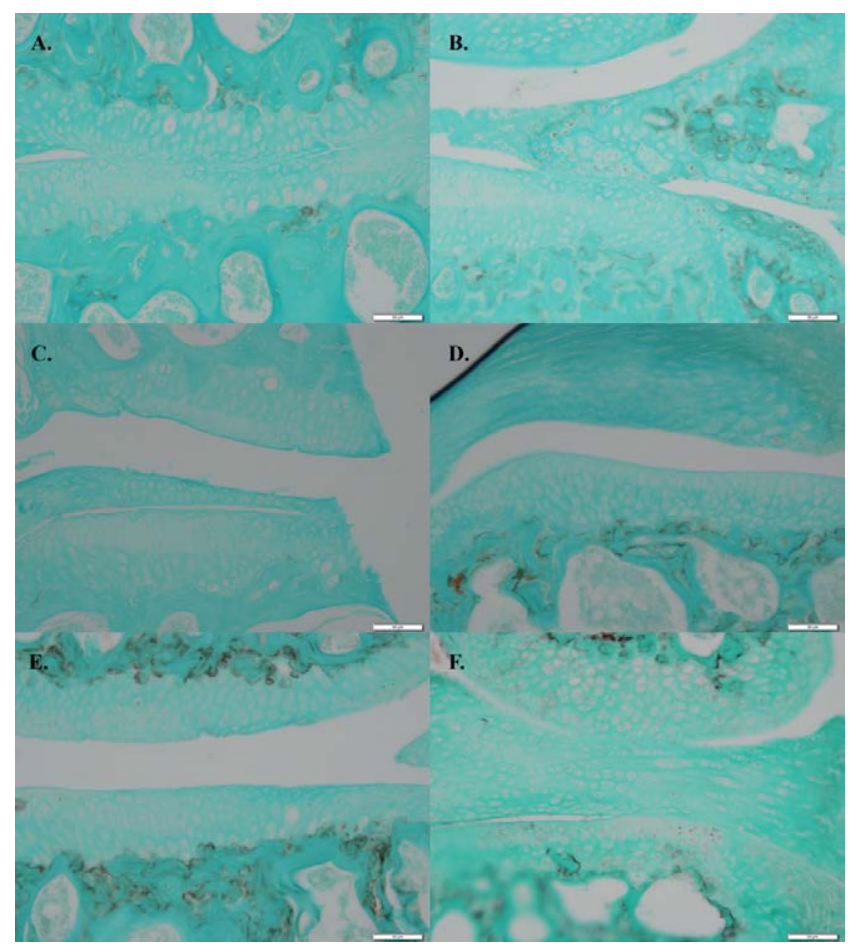

Figure 7: Immunohistochemical staining of knee sections for MmP-13. Knee sections from RAGE KO $(A=0 ; C=0.1 \mathrm{uM} ; E=1 \mathrm{uM})$ and WT mice $(B=0 ; D=0.1$ $\mathrm{uM} ; \mathrm{F}=1 \mathrm{uM})$. Space bar equals $50 \mu \mathrm{m}$.

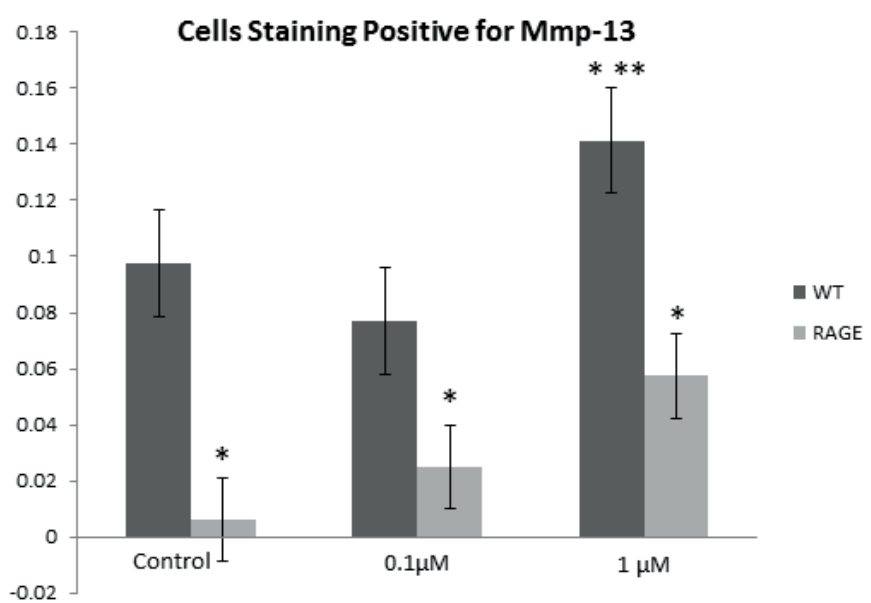

Figure 8: Percentage of cells staining positive for Mmp-13. The percentage of chondrocytes staining positive for Mmp-13 increased dose-dependently with application of TAK-242 in both RAGE KO and wild type mice. The differences between expression in RAGE KO and wild type mice were significant at al concentrations of TAK-242. Wild type mice were $17.288(p<0.0001), 3.266$ $(p=.0078)$, and $2.706(p<0.0001)$ times more likely to stain for Mmp-13 than their RAGE KO counterparts at the control, $0.1 \mathrm{uM}$ and $1 \mathrm{uM}$ treatment levels.

in OA severity in RAGE KO mice with administration of TAK-242 also corresponds with overall low levels of Mmp-13, even though Mmp-13 expression did increase dose-dependently with application of TAK242. This observation demonstrates that when compared to the RAGE signaling pathway, the TLR- 4 inflammatory pathway plays a relatively less important role in OA progression.
Additionally, RAGE KO mice experienced a dose-dependent increase in both TGF-B1 and HtrA1 upon TAK-242 treatment, a finding which is contrary to our previous results which showed a reciprocal relationship between these two biomarkers [3]. These data could indicate that a shared downstream product of the RAGE and TLR-4 is responsible for HtrA1 induced inhibition of Tgf-B1. This is evidenced by a reciprocal relationship between Tgf-B1 and HtrA1 in the wild type mice which, even at high doses of TAK-242, have intact RAGE signaling and the lack of a reciprocal relationship in RAGE KO mice.

The higher incidence of Tgf-B1 in RAGE KO mice also offers additional explanation of the lack of OA progression in these mice. Because Tgf-B1 can exhibit a chondroprotective effect, especially immediately following an injury, the dose-increased levels of Tgf-B1 could have ameliorated the destructive effects of increased Mmp13 as TAK-242 concentration was increased [9,23]. Wild-type mice exhibited lower Tgf-B1 levels at all treatment levels, another possible explanation of more advanced OA in this genotype: Mmp-13 increases were not countered by a chondroprotective increase in Tgf-B1.

Previous studies suggested a chondroprotective effect associated with blocking TLR-4 signaling. The results of our current study show that contrary to expectations, inhibition of TLR-4 signaling following DMM exacerbates OA progression. Previous studies in which TLR-4 was blocked showed a decrease in certain inflammatory biomarkers such as Mmp-13 [17]. It is important to note however, that these previous findings were collected on cultured chondrocytes and not in vivo as in the present study.

It has occurred to us that one explanation of our results is that TAK242 was functioning properly to inhibit TLR-4, and thus there was a reduction of pain which lead to the animal using the joint more than normal following DMM. This could be especially true in the RAGE KO mice since both of these important receptors could have been blocked. The increased use of the joint could have led to the higher OA reported in our scoring. Future studies are planned to test this possibility by examining the downstream signals of TLR-4 (secondary effects) being lessened by TAK-242 compared to vehicle only as well as gait analysis of mice.

Our results suggest the hypothesis that RAGE is much more important than TLR-4 in the progression of OA and that Tgf-B1 exhibits a chondrocyte-protective effect. Additionally, the increased severity of $\mathrm{OA}$ in wild type mice suggests a reduction of pain upon TAK-242 administration and subsequent overuse of the damaged joint. Future studies will be necessary to confirm the effect of TAK-242 on downstream products of TLR-4.

\section{References}

1. Lawrence RC, Felson DT, Helmick CG, Arnold LM, Choi H, et al. (2008) Estimates of the prevalence of arthritis and other rheumatic conditions in the United States. Part II. Arthritis Rheum 58: 26-35.

2. Berenbaum F (2013) Osteoarthritis as an inflammatory disease (osteoarthritis is not osteoarthrosis!). Osteoarthritis Cartilage 21: 16-21.

3. Larkin DJ, Kartchner JZ, Doxey AS, Hollis WR, Rees JL, et al. (2013) Inflammatory markers associated with osteoarthritis after destabilization surgery in young mice with and without Receptor for Advanced Glycation Endproducts (RAGE). Front Physiol 4:121.

4. Holt DW, Henderson ML, Stockdale CE, Farrell JT, Kooyman DL, et al. (2012) Osteoarthritis-like changes in the heterozygous sedc mouse associated with the HtrA1-Ddr2-Mmp-13 degradative pathway: a new model of osteoarthritis. Osteoarthritis Cartilage 20: 430-439.

5. Murwantoko, Yano M, Ueta Y, Murasaki A, Kanda H, et al. (2004) Binding 
Citation: Siebert M, Wilhelm SK, Kartchner JZ, Mecham D, Reynolds PR, et al. (2015) Effect of Pharmacological Blocking of TLR-4 on Osteoarthritis in Mice. J Arthritis 4: 164. doi:10.4172/2167-7921.1000164

of proteins to the PDZ domain regulates proteolytic activity of HtrA1 serine protease. Biochem J 381: 895-904.

6. Polur I, Lee PL, Servais JM, Xu L, Li Y (2010) Role of HTRA1, a serine protease, in the progression of articular cartilage degeneration. Histol Histopathol 25: 599-608.

7. Grimaud E, Heymann D, Rédini F (2002) Recent advances in TGF-beta effects on chondrocyte metabolism. Potential therapeutic roles of TGF-beta in cartilage disorders. Cytokine Growth Factor Rev 13: 241-257.

8. Plaas A, Velasco J, Gorski DJ, Li J, Cole A, et al. (2011) The relationship between fibrogenic TGF $\beta 1$ signaling in the joint and cartilage degradation in post-injury osteoarthritis. Osteoarthritis Cartilage 19: 1081-1090.

9. van der Kraan PM, Blaney Davidson EN, van den Berg WB (2010) A role for age-related changes in TGFbeta signaling in aberrant chondrocyte differentiation and osteoarthritis. Arthritis Res Ther 12: 201.

10. Xu L, Golshirazian I, Asbury BJ, Li Y (2014) Induction of high temperature requirement $A 1$, a serine protease, by TGF-beta1 in articular chondrocytes of mouse models of OA. Histol Histopathol 29: 609-618.

11. Fukami K, Ueda S, Yamagishi S, Kato S, Inagaki Y, et al. (2004) AGEs activate mesangial TGF-beta-Smad signaling via an angiotensin II type I receptor interaction. Kidney Int 66: 2137-2147.

12. Bianchi ME (2007) DAMPs, PAMPs and alarmins: all we need to know about danger. J Leukoc Biol 81: 1-5.

13. Bobacz K, Sunk IG, Hofstaetter JG, Amoyo L, Toma CD, et al. (2007) Tolllike receptors and chondrocytes: the lipopolysaccharide-induced decrease in cartilage matrix synthesis is dependent on the presence of toll-like receptor 4 and antagonized by bone morphogenetic protein 7 . Arthritis Rheum 56: 18801893.

14. van Lent PL, Blom AB, Grevers L, Sloetjes A, van den Berg WB (2007) Tolllike receptor 4 induced FcgammaR expression potentiates early onset of joint inflammation and cartilage destruction during immune complex arthritis: Tolllike receptor 4 largely regulates FcgammaR expression by interleukin 10. Ann Rheum Dis 66: 334-340.
15. Chen YJ, Sheu ML, Tsai KS, Yang RS, Liu SH (2013) Advanced glycation end products induce peroxisome proliferator-activated receptor gamma downregulation-related inflammatory signals in human chondrocytes via Toll-like receptor-4 and receptor for advanced glycation end products. PLoS One 8 : e66611.

16. Shen J, Li S, Chen D (2014) TGFß1 signaling and the development of osteoarthritis. Bone Res 2.

17. Schelbergen RF, Blom $A B$, van den Bosch $M H$, Slöetjes $A$, Abdollahi-Roodsaz $S$, et al. (2012) Alarmins S100A8 and S100A9 elicit a catabolic effect in human osteoarthritic chondrocytes that is dependent on Toll-like receptor 4. Arthritis Rheum 64: 1477-1487.

18. Kawamoto T, li M, Kitazaki T, lizawa Y, Kimura H (2008) TAK-242 selectively suppresses Toll-like receptor 4-signaling mediated by the intracellular domain Eur J Pharmacol 584: 40-48.

19. Xu L, Servais J, Polur I, Kim D, Lee PL, et al. (2010) Attenuation of osteoarthritis progression by reduction of discoidin domain receptor 2 in mice. Arthritis Rheum 62: 2736-2744.

20. Wendt TM, Tanji N, Guo J, Kislinger TR, Qu W, et al. (2003) RAGE drives the development of glomerulosclerosis and implicates podocyte activation in the pathogenesis of diabetic nephropathy. Am J Pathol 162: 1123-1137.

21. Bomsta BD, Bridgewater LC, Seegmiller RE (2006) Premature osteoarthritis in the Disproportionate micromelia (Dmm) mouse. Osteoarthritis Cartilage 14 477-485.

22. Mankin HJ, Dorfman H, Lippiello L, Zarins A (1971) Biochemical and metabolic abnormalities in articular cartilage from osteo-arthritic human hips. II. Correlation of morphology with biochemical and metabolic data. J Bone Joint Surg Am 53: 523-537.

23. Tekari A, Luginbuehl R, Hofstetter W, Egli RJ (2015) Transforming growth factor beta signaling is essential for the autonomous formation of cartilage-like tissue by expanded chondrocytes. PLoS One 10: e0120857. 